\title{
N-Cycling Microbiome Recruitment Differences Between Modern and Wild Zea mays
}

\author{
Alonso Favela, ${ }^{1,2, \dagger}$ Martin Bohn, ${ }^{3}$ and Angela Kent ${ }^{1,2}$ \\ ${ }^{1}$ Program in Ecology, Evolution, and Conservation Biology, University of Illinois at Urbana-Champaign, Urbana, IL 61801 \\ ${ }^{2}$ Department of Natural Resources and Environmental Sciences, University of Illinois at Urbana-Champaign, Urbana, IL 61801 \\ ${ }^{3}$ Department of Crop Sciences, University of Illinois at Urbana-Champaign, Urbana, IL 61801
}

Accepted for publication 28 November 2021.

\begin{tabular}{|c|c|}
\hline $\begin{array}{l}\text { Rewilding modern agricultural cultivars by reintroducing } \\
\text { beneficial ancestral traits is a proposed approach to improve } \\
\text { sustainability of modern agricultural systems. In this study, we } \\
\text { compared recruitment of the rhizosphere microbiome among } \\
\text { modern inbred maize and wild teosinte to assess whether } \\
\text { potentially beneficial plant microbiome traits have been lost } \\
\text { through maize domestication and modern breeding. To do this, } \\
\text { we surveyed the bacterial and fungal communities along with } \\
\text { nitrogen (N)-cycling functional groups in the rhizosphere of six } \\
\text { modern domesticated maize genotypes and ancestral wild } \\
\text { teosinte genotypes, while controlling for environmental } \\
\text { conditions and starting soil inoculum. Using a combination of } \\
\text { high-throughput sequencing and quantitative PCR, we found } \\
\text { that the rhizosphere microbiomes of modern inbred and wild } \\
\text { teosinte differed substantially in taxonomic composition, species } \\
\text { richness, and abundance of N-cycling functional genes. }\end{array}$ & $\begin{array}{l}\text { Furthermore, the modern versus wild designation explained } \\
27 \% \text { of the variation in the prokaryotic microbiome, } 62 \% \text { of the } \\
\text { variation in N-cycling gene richness, and } 66 \% \text { of } \mathrm{N} \text {-cycling gene } \\
\text { abundance. Surprisingly, we found that modern inbred } \\
\text { genotypes hosted microbial communities with higher taxonomic } \\
\text { and functional gene diversity within their microbiomes compared } \\
\text { with ancestral genotypes. These results imply that modern } \\
\text { maize and wild maize differ in their interaction with N-cycling } \\
\text { microorganisms in the rhizosphere and that genetic variation } \\
\text { exists within genus Zea to potentially "rewild" microbiome- } \\
\text { associated traits (i.e., exudation, root phenotypes, and so on). }\end{array}$ \\
\hline
\end{tabular}

Domestication is a strong force shaping the ecological and physiological interactions of an organism (Meyer et al. 2012; Pérez-Jaramillo et al. 2016). Ecologically complex interactions transformed by human domestication of plants range from aboveground chemical defenses (Gaillard et al. 2018; Whitehead et al. 2017) to belowground rhizosphere microbiome interactions (Bulgarelli et al. 2015; Shenton et al. 2016; Pérez-Jaramillo et al. 2018). Although alterations to aboveground chemical defenses have clear consequences for plant productivity (Gaillard et al. 2018;

\section{†Corresponding author: A. Favela; Favela3@illinois.edu}

Funding: Support was provided by the National Science Foundation Integrative Graduate Education and Research Traineeship (NSF IGERT) grant 1069157 and NSF Graduate Research Fellowship Program.

*The $e$-Xtra logo stands for "electronic extra" and indicates that supplementary materials are published online.

The author(s) declare no conflict of interest.

(C) 2022 The American Phytopathological Society
Whitehead et al. 2017), the full implications of domestication's effects on belowground traits such as the rhizosphere microbiome are still unclear. Previously, we have shown that the intense contemporary selection on maize during the Green Revolution resulted in the alteration of microbiome recruitment (Favela et al. 2021). Here, we want to compare Zea spp. that are not altered by modern breeding to determine whether sustainable traits exist in their wild relatives. To improve and potentially rewild our modern agricultural plant cultivars, we need to comprehend the functional consequences of domestication to the plant's microbiome interaction.

The rhizosphere microbiome plays a major role in altering plant fitness and productivity (Lau and Lennon 2012; Philippot et al. 2013a). Microbial taxa present in the rhizosphere have been implicated in providing disease resistance (Cook et al. 1995), amending plant nutrition (Jacoby et al. 2017), improving environmental stress tolerance (Panke-Buisse et al. 2015; Xu et al. 2018), and altering plant phenology (Wagner et al. 2014). Conversely, plant hosts have been shown to selectively recruit microorganisms present in their rhizosphere (Philippot et al. 2013a), a process which has been demonstrated to be heritable across plant cultivars (Favela et al. 2021; Peiffer et al. 2013; Walters et al. 2018). This apparent heritability 
indicates that underlying genetic factors in the host shape how a plant interacts with the soil microbial community. Broadly, plant genetics and evolutionary divergence across plant species have been demonstrated to shape the microbiota that colonizes the plant, yet what this means for rhizosphere microbial community functional groups (i.e., diazotrophs, nitrifiers, and denitrifiers) has been relatively unexplored (Fitzpatrick et al. 2018; Yeoh et al. 2017). Domesticated plant cultivars provide a model to examine the effects of genetic divergence across closely related species (e.g., maize versus sorghum versus wheat), while also providing insight into how anthropogenic influences have transformed the plant's relationship with microbial functional groups important to ecosystem nutrient cycling.

Soil microbial functional groups play a central role in ecosystem nitrogen (N)-cycling processes (Madsen 2011; Pajares and Bohannan 2016; Schimel et al. 2005). In highly fertilized agroecosystems, a significant amount of research has been dedicated to controlling the activities of these $\mathrm{N}$-cycling functional groups to reduce environmental pollution, maintain soil health, and maximize plant N-use efficiency (Drinkwater and Snapp 2007; Philippot et al. 2007; Vitousek et al. 1997). Previously, we have demonstrated that the recruitment of these $\mathrm{N}$-cycling functional groups to the rhizosphere microbiome has unintentionally been altered through selection (Favela et al. 2021). Additionally, we found that more recently developed germplasm recruited fewer microbial taxa with the genetic capability for sustainable $\mathrm{N}$ provisioning and harbored larger populations of microorganisms that contribute to $\mathrm{N}$ losses (Favela et al. 2021). Following from this study, we explored the extent to which maize's ability to recruit a rhizosphere microbiome that contributes to sustainable $\mathrm{N}$-cycling processes has been eroded by domestication of this crop by comparing rhizosphere microbial recruitment between wild teosinte, maize's ancestral progenitor, and modern germplasm.

Maize was domesticated from its wild ancestor teosinte approximately 9,500 years ago in southwestern Mexico (Doebley 2004; Matsuoka et al. 2002). In that time, sweeping genome- and phenome-wide changes occurred, leading maize to be one of the most consequential industrialized crops (Gaudin et al. 2011; Hufford et al. 2012b; Swanson-Wagner et al. 2012; Wright et al. 2005). Additionally, the domestication of maize was associated with a population bottleneck that drastically reduced genomic diversity (Hufford et al. 2012b; Wright et al. 2005) and led to the accumulation of deleterious alleles (Wang et al. 2017) and the development of traits that would be unfit for a wild environment (Diamond 2002; PérezJaramillo et al. 2016). Previous work has determined that teosinte and modern maize rhizosphere microbiomes differ under the same soil environment (Bouffaud et al. 2012, 2014, 2016; JohnstonMonje et al. 2014; Szoboszlay et al. 2015), yet grounding these differences in functional significance has been challenging.

The goal of this study was to determine whether teosinte and inbred maize differed in the recruitment of $\mathrm{N}$-cycling functional groups in the rhizosphere. First, we set out to characterize how the domestication status of the Zea mays cultivar influenced the diversity and composition of the bacterial and fungal rhizosphere microbiome. Specifically, we wanted to determine whether prokaryotic and fungal taxonomic domains are both affected by the domestication status of a cultivar. Second, we examined differences in domesticated and wild Z. mays in recruiting assemblages of microbial functional groups involved in $\mathrm{N}$ fixation, nitrification, and denitrification. This study sheds light on the potential impact of domestication on sustainable $\mathrm{N}$-cycling processes in the maize rhizosphere. Understanding whether there is a functional difference in the wild plant microbiome compared with the microbiome of modern crop cultivars could be potentially useful in identifying (and recovering) traits involved in sustainability that were lost during domestication and crop improvement.

\section{MATERIALS AND METHODS}

Line selection and greenhouse experiment. The goal of this experiment was to determine whether maize and teosinte differed in rhizosphere microbiome recruitment under greenhouse conditions. Twelve cultivar lines were selected for comparison: 6 modern maize inbred lines and 6 wild teosintes. Within teosinte, two subspecies were selected: Z. mays subsp. mexicana and Z. mays subsp. parviglumis. These subspecies originated from distinct biogeographic regions in Mexico, and are the closest related subspecies to modern maize (Hufford et al. 2012a). Metadata about the genotypes is presented in Supplementary Table S1.

Zea seed stocks were obtained from the United States Department of Agriculture North Central Regional Plant Introduction Station (Ames, IA) and the Maize Genetics Cooperation Stock Center (Urbana, IL).

Seeds were surface sterilized by soaking for 5 mins in $8.25 \%$ $\mathrm{NaClO}$, followed by one rinse with sterilized distilled water, a single rinse of $70 \%$ ethanol, and three rinses with sterile distilled water. Surface-sterilized seeds were dried on sterile filter paper in a sterile petri dish, then stored at $4^{\circ} \mathrm{C}$ overnight before sowing.

Zea lines were grown in greenhouse conditions to isolate the effects of genotype on the microbiome. Planting medium was a combination of live and steam-pasteurized soil mix. The live inoculum soil was collected from agricultural soil located on the Crop Sciences Research and Education Center-South Farms at the University of Illinois at Urbana-Champaign, Urbana, IL. $\left(40^{\circ} 03^{\prime} 31.0^{\prime \prime} \mathrm{N}, 88^{\circ} 14^{\prime} 13.4^{\prime \prime} \mathrm{W}\right)$. At the time, the soil was out of agricultural rotation (corn-soy) for at least 2 years. Inoculum soil was sieved $(2 \mathrm{~mm})$, then added $(10 \%)$ to a steam-pasteurized mix of soil-calcined clay-torpedo sand (1:1:1). An inoculum sample was collected before plant growth to characterize the microbiome before plant treatment.

For each genotype, 10 classic 600 pots (2-gallon, $\approx 41$ liters) were sown with three seeds in each. Pots were thinned a week after germination, leaving only a single plant per pot for the remainder of the growth. In total, 120 plants were included in the study. They were placed in a completely randomized design in the greenhouse with $16 \mathrm{~h}$ of light and $8 \mathrm{~h}$ of darkness. All plants were connected to an irrigation system that fertilized plants twice a week. Plants were fertilized with a liquid nutrient solution, specifically Cal-Mag (15-5-15), at a rate of $150 \mathrm{ppm} . \mathrm{N}$ was applied as $11.8 \%$ nitrate $\mathrm{N}$, $1.1 \%$ ammoniacal $\mathrm{N}$, and $2.1 \%$ urea $\mathrm{N}$. All plant treatments were maintained under the same fertilizer regime. These fertilization conditions are typical for modern maize grown in the Midwest.

Roots were harvested 36 days after emergence. Plants were approximately at the V4-V5 growth stage with four to five fully collared leaves. Plant rhizospheres were harvested by extracting root systems from the soil and shaking them vigorously to separate soil that was not tightly bound to roots. Rhizosphere soil was extracted by placing the root system in a 1-liter bottle with $40 \mathrm{ml}$ of sterile distilled water and shaking vigorously for $5 \mathrm{~min}(\mathrm{Li}$ et al. 2016). The resulting soil slurry was placed into 50-ml centrifuge tubes and lyophilized before DNA extraction from $500 \mathrm{mg}$ of lyophilized soil using the FastDNA for Soil DNA extraction kit, according to the manufacturer's instructions (MPBio, Solon, OH, U.S.A.). DNA was further purified using cetyltrimethyl ammonium bromide extraction to remove contaminating humic acids (Sambrook and Russell 2001). Water controls were included in extractions and DNA sequencing. Rhizosphere samples of all 10 replicates for each genotype were harvested separately for molecular analysis. 
Microbial community amplicon sequencing. For this experiment, we characterized microbial functional groups related to three major transformations that occur in the $\mathrm{N}$ cycle: $\mathrm{N}$ fixation, nitrification, and denitrification. Amplicon sequencing was performed on prokaryotic $16 \mathrm{~S}$ ribosomal RNA (rRNA) V4 region genes, fungal internal transcribed spacer (ITS)2, and diagnostic genes for $\mathrm{N}$-cycling transformations: bacterial amoA, archaeal amoA, nirS, nirK, nos Z, and nifH genes. The Fluidigm Access Array IFC chip was used to prepare sequencing amplicons (Fluidigm, San Francisco, CA, U.S.A.). This method allows for the simultaneous amplification of target functional genes using multiple primer sets. Primer information is provided in Supplementary Table S2. Fluidigm amplification and Illumina sequencing were conducted at the Roy J. Carver Biotechnology Center, University of Illinois (Urbana, IL, U.S.A.). To increase the amount of template DNA prior to Fluidigm, a preamplification (specific target amplification [STA]) reaction was performed in $5-\mu \mathrm{l}$ reaction mixtures containing $2 \times$ TaqMan PreAmp Master Mix (Applied Biosystems), $0.5 \mu \mathrm{M}$ each primer, and $1.25 \mu \mathrm{l}$ of the DNA template. The STA reaction was performed on an MJ Research Tetrad thermal cycler with the following cycling program: $95^{\circ} \mathrm{C}$ for $10 \mathrm{~min}$ followed by 14 cycles of $95^{\circ} \mathrm{C}$ for $15 \mathrm{~s}$ and $58^{\circ} \mathrm{C}$ for $4 \mathrm{~min}$.

Fast Length Adjustment of Short reads (Magoč and Salzberg 2011) software was used to merge paired-end sequences from $16 \mathrm{~S}$ rRNA genes. For functional genes and fungal ITS, only forward read sequences were used. Once reads were merged, they were filtered by quality using the FASTX-Toolkit (Gordon and Hannon 2014). Reads that did not have a minimum quality score of 30 across $90 \%$ of the bases were removed. Using the FASTX Toolkit, nirK reads were trimmed to its amplicon size of $165 \mathrm{bp}$.

Once quality preprocessing was performed, FASTQ reads were converted to FASTA format. Using USEARCH-UPARSE version 8.1 (Edgar 2010), sequences were binned into discrete operational taxonomic units (OTUs) based on 97\% similarity and singleton DNA sequences were removed. Quantitative Insights into Microbial Ecology (QIIME) was used to generate OTU tables for downstream statistical analysis and to assign taxonomic information; this is done with a combination of the UCLUST algorithm and Greengenes database (Caporaso et al. 2010; DeSantis et al. 2006; Edgar 2010). Once taxonomy was assigned, chloroplast, mitochondrial, and protist OTUs were removed from the dataset. Rarefaction was performed to correct for differential sequencing depth across samples. Taxonomy was also assigned for functional gene sequences using QIIME (Caporaso et al. 2010) with the BLAST (Altschul et al. 1997) algorithm and custom gene-specific databases generated from reference sequences obtained from the FunGene repository (http://fungene.cme.msu.edu/) (Fish et al. 2013). All OTU tables used in statistical analyses were generated in QIIME. Singleton OTUs were filtered prior to statistical analysis.

The number of raw reads generated from sequencing run, reads present after quality filter, and the rarefaction level of reads per sample for 16S rRNA, ITS, and N-cycling genes are reported in Supplementary Table S3. Amplicon sequence data for 16S rRNA genes, fungal ITS2 region, and N-cycling functional genes is available for download on the NCBI Sequence Read Archive database at accession number PRJNA753114 (https://www.ncbi.nlm.nih.gov/ bioproject/PRJNA753114/). Code for sequence processing and statistical analysis is presented at GitHub (https://github.com/favela3/ Phytobiome2021.Supplemental).

Quantifying N-cycling functional groups. Quantitative PCR (qPCR) was used to determine the abundance of functional genes in each of the rhizosphere microbial communities. STA, described by Ishii et al. (2014), was carried out on samples and standards to increase template DNA for amplification. STA and qPCR master mix recipes from (Edwards et al. 2018) were used for all samples. STA product and qPCR master mix were loaded into the Dynamic Array Microfluidics Fluidigm Gene Expression chip, where amplification and quantification of functional genes were carried out simultaneously (Fluidigm). All samples and standards were analyzed in 12 technical replicates. Fluidigm Real-Time PCR Analysis software version 4.1.3 was used to calculate gene threshold cycles $\left(C_{T}\right) . C_{T}$ values were converted to gene copy number using gene length and standard curves. All Fluidigm qPCR was conducted at the Roy J. Carver Biotechnology Center. The final copy number of each functional gene amplicon was standardized by the nanograms of template DNA in the qPCR amplification.

Statistical analysis. The microbial communities were evaluated as separate datasets for each amplicon (16S rRNA, fungal ITS, nifH, nosZ, nirK, nirS, bacterial amoA, and archaeal amoA).

The relative effect of $Z$. mays genotype and domestication on the rhizosphere microbiome composition was assessed using permutational analysis of variance (PERMANOVA) with the 'adonis' function, from the community ecology R package 'vegan' (Oksanen et al. 2007). To visualize differences from these models, nonmetric multidimensional scaling ordinations were created using $\mathrm{R}$ package 'phyloseq' and plotted with R package 'ggplot2' (McMurdie and Holmes 2013; Wickham et al. 2007). Significant differences in functional gene abundance were evaluated using an analysis of variance (ANOVA) model and the Tukey's honestly significant difference (HSD) test from the 'stats' package in base R (R Core Team 2013). Using the 'asreml-r' package (Butler et al. 2017), additional restricted maximum-likelihood mixed-effects models were used to determine qPCR differences between domesticated and wild cultivars. 'DESeq2' was used to determine OTUs that were significantly different in relative abundance by using a pairwise comparison among domestication groups (Love et al. 2014).

To control for the variance within individual genotypes when performing our analysis for domestication effects, we used the mean microbiome for each genotype (referred to as the genotypic mean microbiome). These mean microbial communities were generated using the 'aggregate' function in base R; here, this function was used to find the mean of the amplicon data matrix based on the 10 replicates within each genotype.

\section{RESULTS}

Domestication status influences the taxonomic rhizosphere microbial community. Modern inbred maize, teosinte, and the starting bulk soil inoculum all exhibited differences in the composition and richness of their microbial communities (Fig. 1; Supplementary Tables S4 to S7). In summary, we identified 15,072 different 16S rRNA OTUs (97\% similarity), and 1,027 fungal OTUs were identified from the ITS2 region. The factor plant genotype $(n=12)$ explained a significant amount of variance in the rhizosphere microbiome (PERMANOVA prokaryotic: $\mathrm{DF}=11 R^{2}=$ $0.18, P<0.001$; fungal: $\mathrm{DF}=11, R^{2}=0.15, P<0.003$ ) (Supplementary Tables S4 and S5). To focus on domestication effects, we carried out our remaining analyses on the genotype-mean microbial community as described in the methods. Our analysis of the genotype-mean microbiome revealed that domestication status explained $27 \%$ of the variation of the prokaryotic $16 \mathrm{~S}$ rRNA and $21 \%$ of the variation in fungal ITS (Fig. 1A and C) (prokaryotic, $\mathrm{DF}=1 P<0.01$, fungal, DF $=1 P<0.004$, Supplementary Tables S6 and S7). Furthermore, domesticated maize exhibited higher levels of species richness in their prokaryotic and fungal microbial communities compared with wild teosinte (Fig. 1B and D) (ANOVA, Tukey's HSD, prokaryotic: $n=60, P<0.05$; fungal: $n=60, P<0.05)$. 
DESeq2 analysis revealed that domestication status influenced microbial membership of 346 different prokaryotic taxa $(\alpha=0.01)$. Of these, 260 OTUs were present in greater relative abundance in the inbred maize rhizosphere, while 86 had greater relative abundance in the teosinte rhizosphere microbiome (Fig. 2A; Supplementary Fig. S2A). Domesticated maize enriched OTUs across most of the major bacterial phyla but the differences were especially pronounced in Proteobacteria and Bacteroidetes (Fig. 2A; Supplementary Figs. S3 and S4), although teosinte microbiomes had greater abundance of Firmicutes, Verrucomicrobia, and Actinobacteria (Fig. 2A; Supplementary Fig. S3). Supplemental materials include plots of lower taxonomic levels (Supplementary Figs. S2 to S4). For the fungal microbiome, we found that domestication status influenced membership of 48 different fungal taxa $(\alpha=0.01)$. Of these, 37 had greater representation in the rhizosphere of modern inbred maize, while 11 were in greater relative abundance in the teosinte microbiome (Fig. 2B; Supplementary Fig. S2B). Differences in the fungal abundance were primarily driven by enrichment of Ascomycota OTUs in the inbred maize microbiome and, secondarily, in Basidomycota OTUs.

Domestication status influences the $\mathrm{N}$-cycling genes present in the rhizosphere. Diversity, composition, and abundance of $\mathrm{N}$-cycling functional groups were altered by domestication status of host plants (Figs. 3 and 4; Supplementary Table S8). We observed 1,498 nifH OTUs, 95 archaeal amoA OTUs, 200 bacterial amoA
OTUs, 8,632 nirK OTUs, 1,186 nirS OTUs, and 1,864 nosZ OTUs. Specifically, we observed that functional genes nifH, bacterial amoA, nirK, nirS, and nos $Z$ were all significantly altered in composition in response to domestication status (Fig. 4; Supplementary Table S9). Variation in $\mathrm{N}$ fixation and nitrification functional group communities were most influenced by domestication status (PERMANOVA, nifH: $\mathrm{DF}=11, R^{2}=0.27, P<0.003$; bacterial amoA: $\left.\mathrm{DF}=11, R^{2}=0.22, P<0.009\right)$ (Supplementary Table S9). Modest amounts of variation in denitrification functional groups were explained by domestication status (PERMANOVA, nirK: DF $=11$, $R^{2}=0.11, P<0.001$; nirs: DF $=11, R^{2}=0.16, P<0.004$; nosZ: $\mathrm{DF}=11, R^{2}=0.13, P<0.006$ ) (Fig. 4; Supplementary Table S9). Furthermore, nifH, bacterial amoA, nirS, and nos $Z$ were all significantly more diverse in the domesticated maize rhizosphere compared with the teosinte rhizosphere (Fig. 3A) (Wald's test: $P<$ 0.05; increase relative to teosinte: nifH $10 \%$, bacterial amoA $27 \%$, nirs $100 \%$, and nosZ 70\%). Archaeal amoA did not show significant differences in gene composition or richness across domestication classes. Additionally, qPCR results showed that domesticated maize cultivars had lower copy numbers of archaeal amoA, bacterial amoA, and nirK compared with teosinte (Fig. 3B) (Supplementary Table S10) (Wald's test: $P<0.05$; reduction relative to teosinte: nifH $77 \%$, bacterial amoA $62 \%$, and nirK $32 \%$ ). In addition to this, $\alpha$ diversity and abundance results showed an inverse relationship at the genotype level between functional gene diversity and abundance.
A

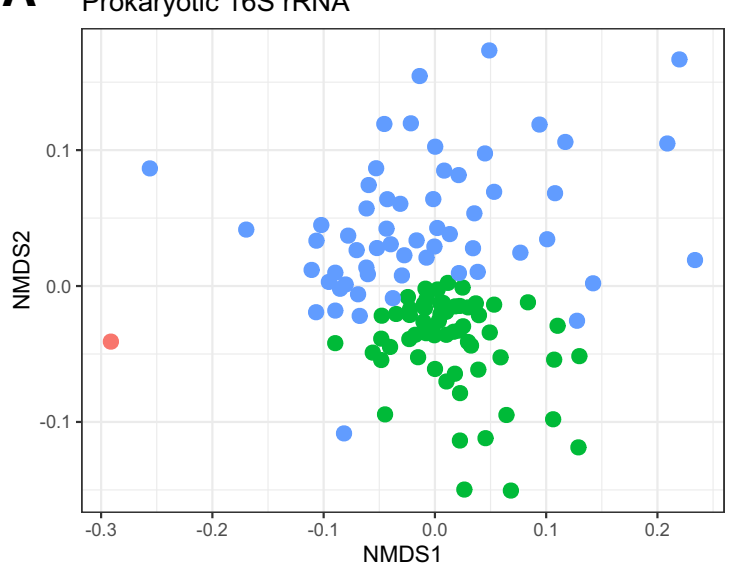

C Fungal ITS

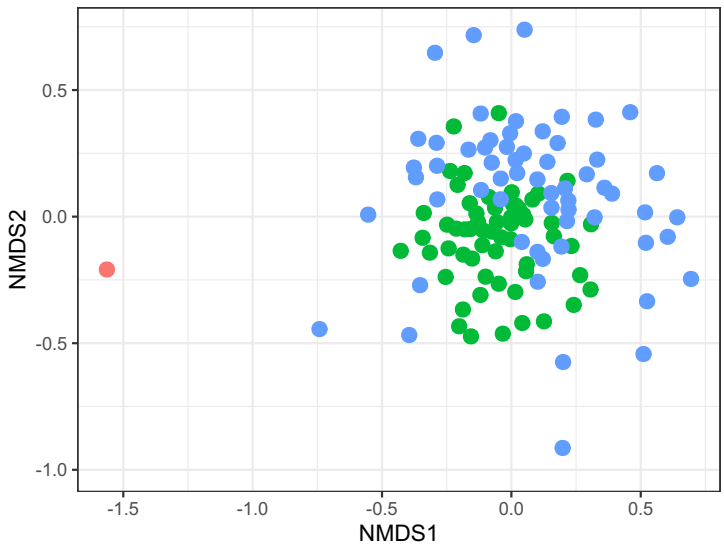

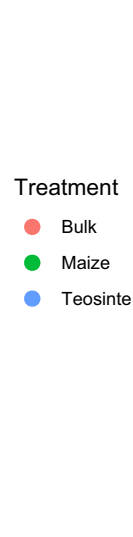

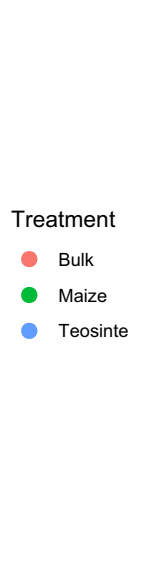

B

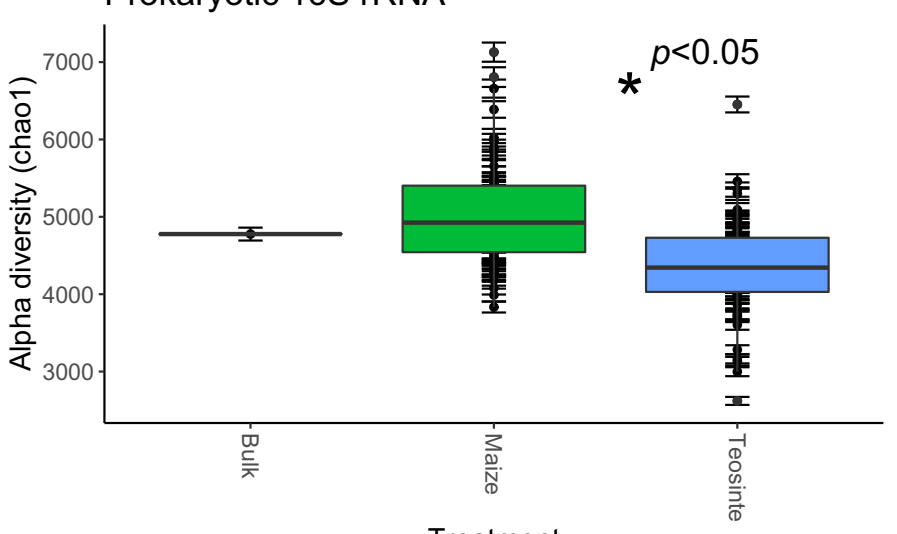

Treatment

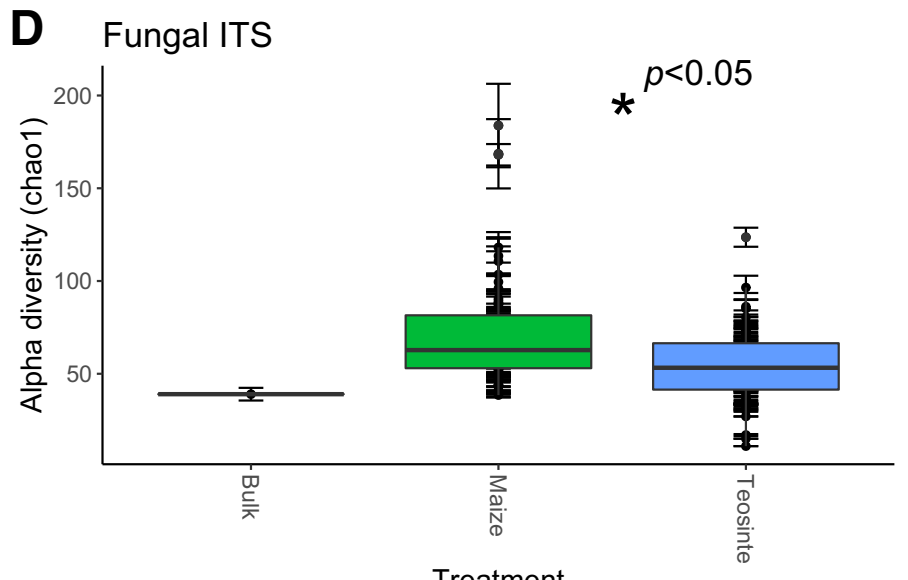

Treatment

Fig. 1. Nonmetric multidimensional scaling (NMDS) ordinations based on Bray-Curtis dissimilarity among A and B, prokaryotic $16 \mathrm{~S}$ ribosomal RNA (rRNA) and C and D, fungal internal transcribed spacer (ITS) rhizosphere microbiome samples compared among inbred maize, teosinte, and bulk soil. Statistics presented in the figure show permutational analysis of variance model results (Supplementary Tables S4 to S7). B and D, $\alpha$ diversity (Chao1) of the rhizosphere microbiome compared among inbred maize, teosinte, and bulk soil. The rhizosphere microbiome of inbred maize and teosinte have significantly different $\alpha$ diversity values $(t$ test: $P<0.05)$. 
Regression analysis revealed a strong negative relationship between gene abundance and diversity (Supplementary Fig. S1) $(r=-0.731$, $P<0.0123)$. Overall, domestication status explained $62 \%$ of the variation in mean richness of $\mathrm{N}$-cycling functional groups among genotypes (PERMANOVA: DF $=1, P<0.003$ ) (Supplementary Table S11.1) and $65 \%$ of the variation in average abundance of N-cycling functional groups (PERMANOVA: DF $=1, P<0.005$ ) (Supplementary Table S11.2).

\section{DISCUSSION}

In this study, we show that modern maize and teosinte recruit distinct microbial assemblages, and that these differences extend to
$\mathrm{N}$-cycling functional groups within the microbiome. These findings suggest that domestication and selection have resulted in altered microbiome and $\mathrm{N}$-cycling functional gene recruitment within the Z. mays rhizosphere (Fig. 1). These results align with previous studies showing differences in rhizosphere microbiome recruitment between teosinte and modern maize (Brisson et al. 2019; JohnstonMonje et al. 2014; Schmidt et al. 2020). This study builds on previous maize and teosinte research by showing that, at least in the greenhouse, the rhizosphere microbiome of inbred maize displayed greater microbial diversity than rhizosphere microbial assemblages in teosinte. This finding suggests that domesticated maize lines have either an enhanced ability to maintain higher levels of diversity in the rhizosphere or a weakened ability to filter taxa from the

\section{A Prokaryotic 16S rRNA}

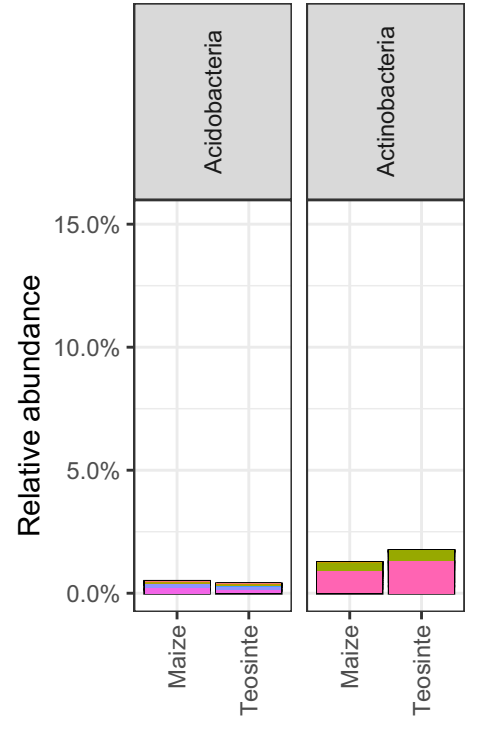

\section{B Fungal ITS}

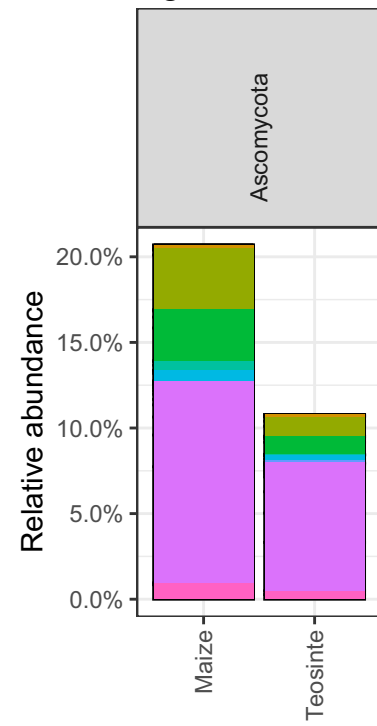

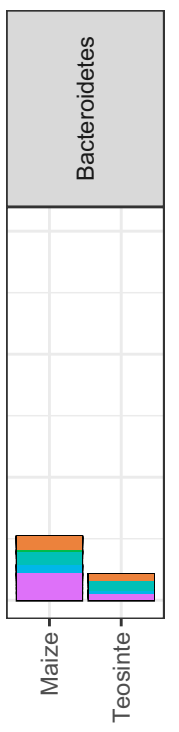
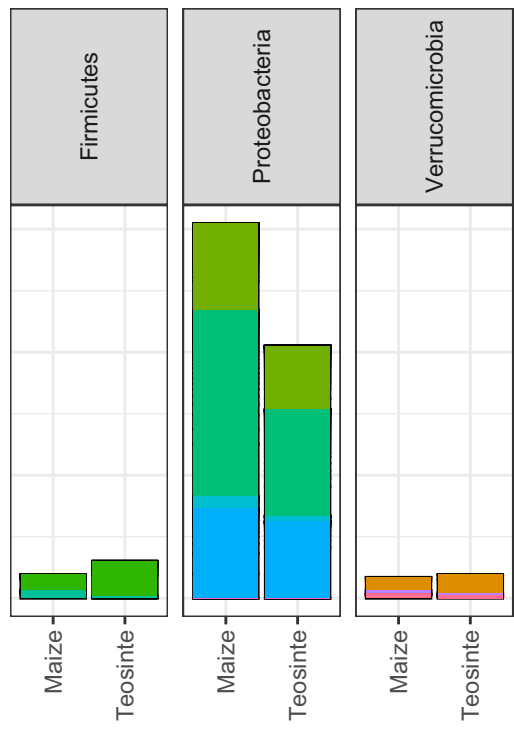

Treatment
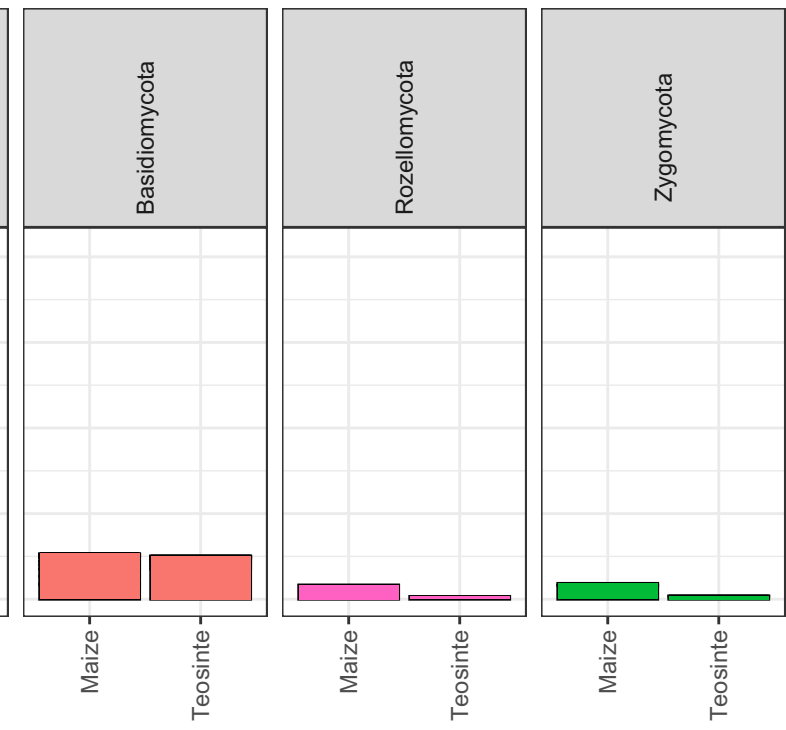

Treatment

Fig. 2. Microbial operational taxonomic units (OTUs) that differed significantly between inbred maize and teosinte rhizospheres were identified by DESeq2. A, Relative abundance of differential abundant prokaryotic $16 \mathrm{~S}$ ribosomal RNA (rRNA) OTUs faceted by phylum. B, Stack plots show the relative abundance of differential abundant fungal internal transcribed spacer (ITS) OTUs faceted by phylum. Grayscale within stack plots is included to show taxonomic class identity. List of OTUs differential enriched and stack plots within highly abundant taxonomic groups is included in Supplementary Figures S2 to S4. 
rhizosphere. Coinciding with this diversity increase, a greater abundance of copiotrophic bacteria (Proteobacteria) and potential pathogenic fungi (Ascomycota) (Berbee 2001; Favela et al. 2021; Fierer et al. 2007) was observed in the modern maize rhizosphere (Fig. 2). In addition to this, we observed a negative correlation between functional gene diversity and abundance, suggesting a tradeoff between these measures for recruitment (Supplementary Fig. S1). The microbial composition data in combination with the functional gene diversity-abundance relationship supports the latter "weakened filter" hypothesis. Research on the effects of domestication on arbuscular mycorrhizal (AM) symbiosis across 27 crop species (Martín-Robles et al. 2018) found that domesticated cultivars maintained less efficient AM symbiosis with a weakened ability to downregulate colonization under high nutrient conditions shifting their symbiosis from mutualistic to parasitic (Martín-Robles et al. 2018). A parallel process with domestication could be occurring with whole-microbiome regulation as observed in the present study, characterized by modern maize having a "weakened filter" to curb the growth of copiotrophic prokaryotes and pathogenic fungi.

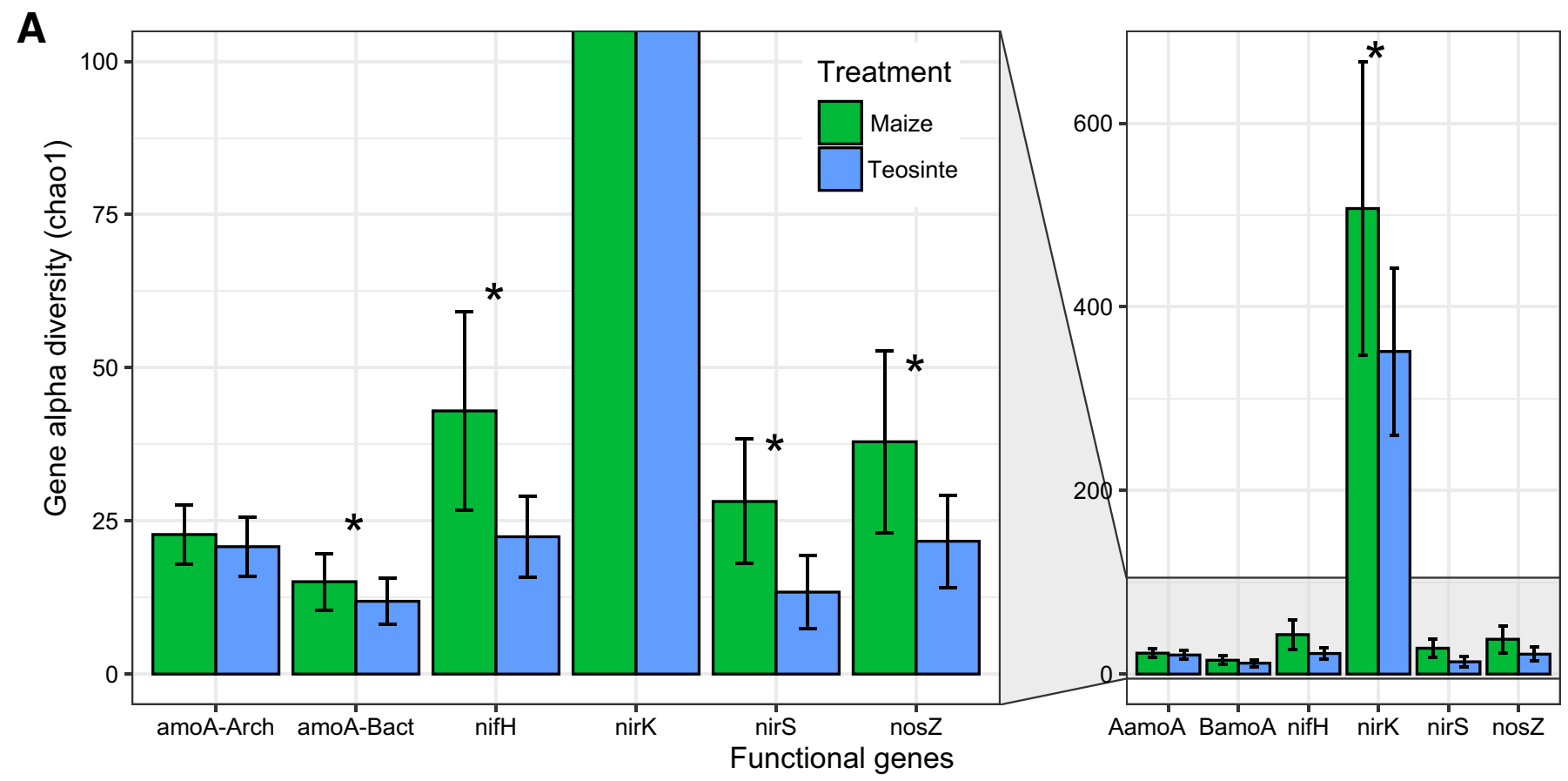

B

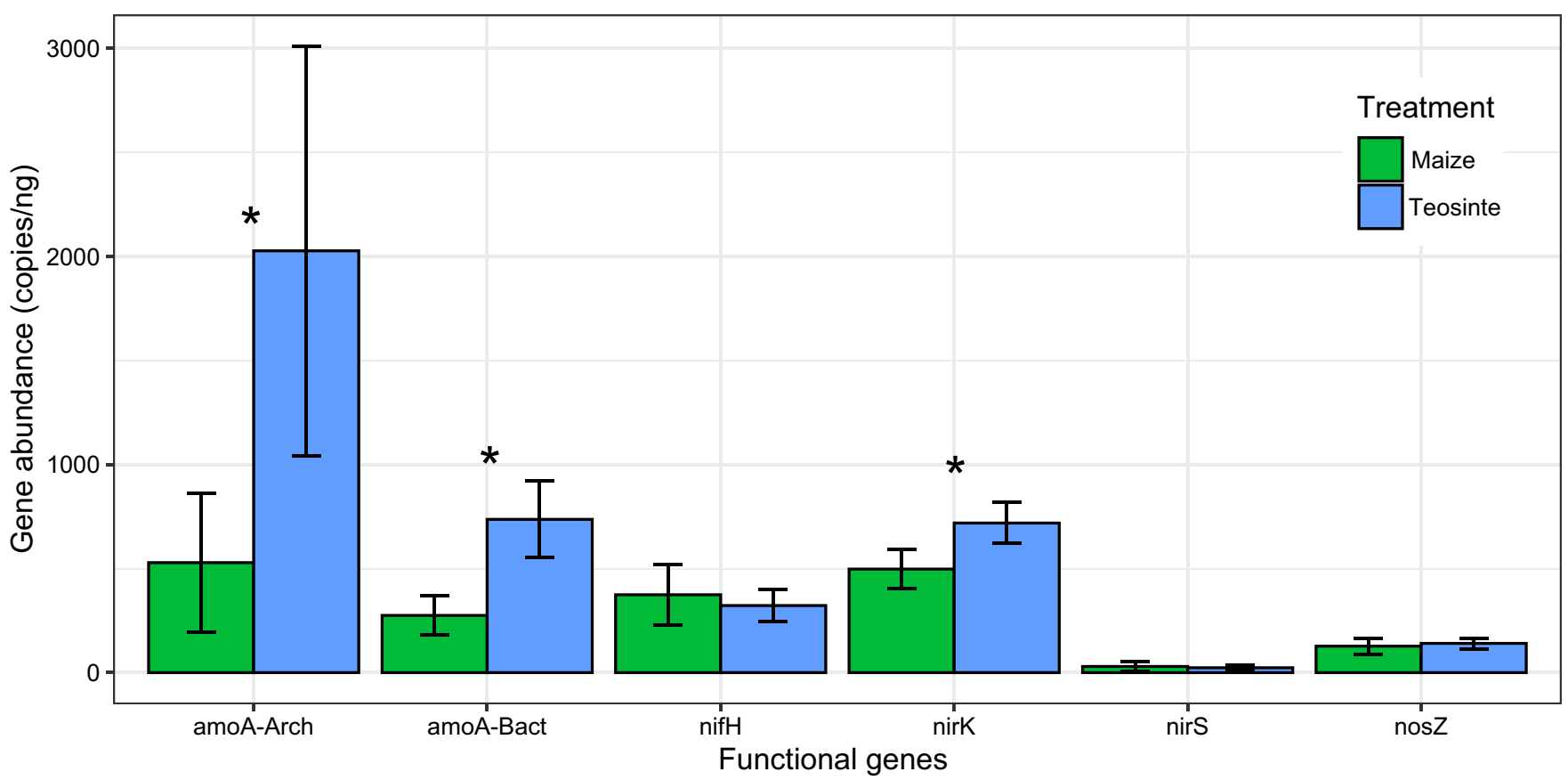

Fig. 3. Functional gene $\alpha$ diversity and abundance were compared between the maize and teosinte rhizosphere. A, Gene $\alpha$ diversity (Chao1) across the functional genes measured in this study. Note that the axis is replotted to correct for the high richness observed for the nirK gene. B, Gene abundance (copies per nanogram) compared among microbial functional genes; * indicates $P<0.05$. 
To gain an idea of the potential functional consequences associated with the shift in rhizosphere microbiome, we took a targeted functional gene approach, through the sequencing and quantification of diagnostic N-cycling genes. Understanding how specific functional groups respond to the unique rhizosphere effect presented by domesticated and wild plant genotypes could be informative for how these microorganisms are processing $\mathrm{N}$ in the environment in proximity to the roots (Kuypers et al. 2018; Pajares and Bohannan 2016). We focused on diversity and abundance of functional genes related to denitrification, nitrification, and $\mathrm{N}$ fixation and found that domestication played a role in shaping the functional groups related to all of these processes (Figs. 3 and 4; Supplementary Fig. S1). Modern maize genotypes appeared to have higher diversity of $\mathrm{N}$-cycling functional groups (bacterial amoA, nifH, nirK, nirS, and nosZ) in the rhizosphere compared with teosinte genotypes, while teosinte genotypes had higher abundance of some functional groups (archaeal $a m o A$, bacterial $a m o A$, and nirK). This negative relationship between abundance and diversity suggests a trade-off in plant-microbe interactions similar to those seen in AM-plant interactions (Porter and Sachs 2020; Xing et al. 2012). Additionally, this counterintuitive disjunct between the $\mathrm{N}$-cycling gene diversity and abundance suggests different mechanisms of microbiome interaction across teosinte and maize. With teosinte appearing to be more selective of the $\mathrm{N}$ transformers it allows to persist in the rhizosphere (lower diversity), it is also more effective in its propagation of those $\mathrm{N}$-cycling functional groups (higher abundance). This functional gene abundance-diversity relationship is interesting because there is no well-established understanding for which microbiome genotypes are most predictive of specific N-cycling function phenotypes in soils (Ma et al. 2019; Morris et al. 2020). Some research in this area suggests that diversity is a more significant predictor of ecosystem function (Philippot et al. 2013b) while studies show abundance to be more important (Ouyang et al. 2018). Further work is needed across a wide range of plants and soil types to disentangle the diversity-abundance-function relationship.

Diazotrophs were not significantly different in abundance (qPCR) between teosinte and inbred maize. This finding was not surprising because the plants were fertilized with $\mathrm{N}$ during the growing period, and diazotrophs would have no competitive advantage under $\mathrm{N}$-sufficient conditions. As with other functional groups,

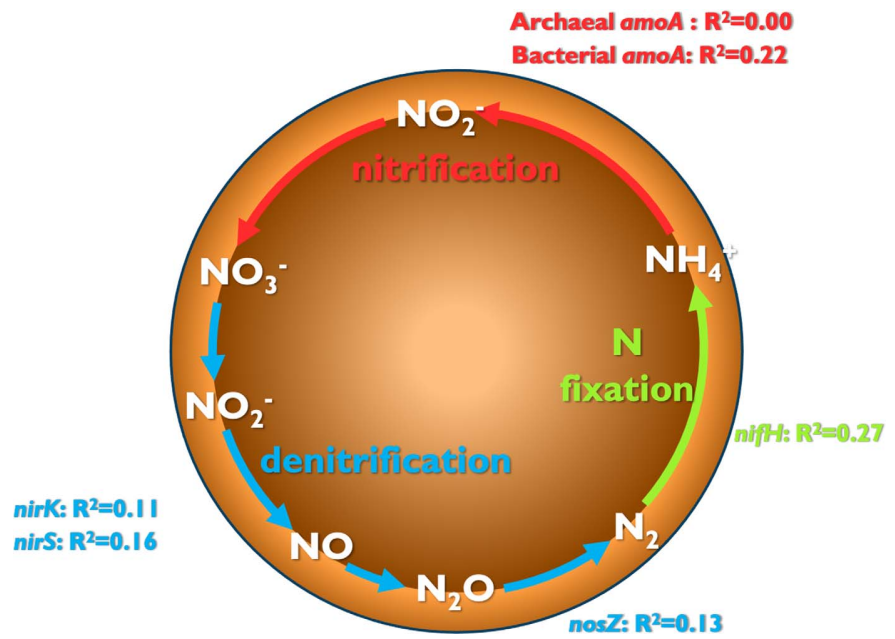

Fig. 4. Key transformations in nitrogen $(\mathrm{N})$ cycle where the domestication status influenced the composition of the groups. Percentages denote the amount of variance in the functional gene composition explained by the domestication factor in permutational analysis of variance. the maize rhizosphere hosted a considerable amount of diversity (Chao1) in nifH -we attribute this higher diversity to a potential inability to filter microbial colonization in their rhizosphere, as mentioned above. Recent research has revealed that some maize landraces exude complex sugars from their aerial roots that can host N-fixing microbes (Van Deynze et al. 2018). This research has highlighted the fact that maize can have a mutualistic relationship with diazotrophs that is more complex than previously understood. In addition, we have seen that, within elite inbred maize, the modern breeding process has resulted in reduced nifH abundance (qPCR) and altered composition in the rhizosphere since the 1940s (Favela et al. 2021). Further research needs to be carried out under a variety of field $\mathrm{N}$ conditions to understand whether these findings were caused by the domestication bottleneck and subsequent selection or are due to effects of fertilization (or some combination of selection and nutrient environment).

Regarding nitrification functional groups, we were surprised to find that both archaeal and bacterial amoA were in higher abundance but lower in diversity in the teosinte rhizosphere compared with the maize rhizosphere. This result was surprising because nitrification is commonly thought of as a process that competes with plants for available $\mathrm{N}$ and can lead to considerable losses of $\mathrm{N}$ from the agroecosystem (Moreau et al. 2019; Subbarao et al. 2013). Furthermore, in other cereal grass species (i.e., sorghum, signalgrass, and rice), it has been shown that some plant varieties, typically not domesticated, can produce secondary toxic compounds that biologically inhibit nitrifier function (Coskun et al. 2017a, b). Based on this prior research, we can hypothesize that teosinte would have these biological nitrification inhibition phenotypes, thereby displaying lower nitrifier diversity and abundance in the rhizosphere. Although we did observe teosinte having lower diversity of nitrifiers and recruitment of different nitrifiers assemblages compared with modern maize, the high copy numbers of amoA remained puzzling. Previous research in nitrifying bacteria (Nitrospira) has shown that closely related species can contain a large degree of functional diversity (Gruber-Dorninger et al. 2015; Spasov et al. 2020). This functional diversity allows the group to partition available niches and specialize on environmental gradients (GruberDorninger et al. 2015; Spasov et al. 2020). The rhizosphere is full of steep gradients formed by nutrient uptake, enzyme activity, and carbon release from the root. These nutrient gradients (e.g., ammonium) in the rhizosphere could result in the maintenance of higher nitrifier diversity. Furthermore, nitrifiers are quite sensitive to allelopathy and changes in $\mathrm{pH}$ (Coskun et al. 2017a, b). Therefore, the higher nitrifier diversity in the rhizosphere may allow for more efficient use of the available niche space, leading to improved performance of nitrification. Conversely, high abundance of nitrifiers with limited diversity will have a more inefficient usage of the available niche space and be limited to a specific set of optimal nitrification conditions. Next steps would be to determine whether the differential recruitment and colonization by nitrifiers persists under field conditions and leads to changes in functions related to sustainability.

In addition, we observed that the domestication status of $Z$. mays species influenced genes that are diagnostic for denitrification functional groups (Fig. 3). Denitrification genes responsible for the conversion of nitrite into nitric oxide showed differences in abundance, with nirK being more abundant in the teosinte rhizosphere and nirS and nirK having higher diversity in the maize rhizosphere. Previous work has shown that nirS-type denitrifiers are more sensitive to plant allelopathic rhizosphere effects compared with nirK-type, and that nirK communities have a broader profile for carbon substrate utilization (Bardon et al. 2016; Hou et al. 2018). Perhaps, higher nirS diversity in the maize rhizosphere is caused by having a 
weaker rhizosphere filter, whereas increases in nirK abundance could be attributed to teosinte's likely more complex metabolic profile (Xu et al. 2019). Furthermore, studies have shown that the response of nirS and nirK functional groups to moisture and nutrient gradients are markedly different, which supports the possibility that the two communities occupy different ecological niches (Azziz et al. 2017; Jones and Hallin 2010; Wei et al. 2015). To the denitrification functional groups, the maize and teosinte rhizosphere present different ecological niches generated by altered patterns in plant exudation. Reduced richness in the denitrifier community may hint at teosinte being able to perform biological denitrification inhibition (BDI) (Bardon et al. 2016). BDI, originally described in Fallopia spp., has been defined as the ability of the plant to release secondary metabolites (such as procyanidins) that inhibit denitrifiers and, therefore, conserve nitrates in the rhizosphere environment (Bardon et al. 2014). Furthermore, studies across a number of species have shown that exudates from a variety of plant species have the ability to alter denitrification abundance and activity (Achouak et al. 2019). A key challenge will be understanding the host genes and subsequent related secondary metabolites driving these functional group differences.

We hypothesize that our differences in nitrifier and denitrifier communities between maize and teosinte are caused by differences in the production and exudation of plant secondary compounds. Many recent comprehensive studies examining transcriptome and metabolomic differences between maize and teosinte have shown that alkaloids, terpenoids, lipids, and benzoxazinoids and their regulation has been altered during maize domestication (Wang et al. 2018; Xu et al. 2019). We propose that these genetic and chemical changes in maize result in altered recruitment of N-cycling functional groups in the rhizosphere and may even alter how maize obtains nutrients from the soil matrix. The observation that maize and teosinte differ in recruitment of microbiome groups throughout the $\mathrm{N}$ cycle (Fig. 4) is important because these functional groups play a central role in the movement of $\mathrm{N}$ in the agroecosystem (Bowles et al. 2018; Kuypers et al. 2018).

Determining the function of these lost or altered ancestral plant microbiome traits will inform us about their potential for use in agriculture. Currently, a substantial fraction of $\mathrm{N}$ fertilizer applied to arable lands is often lost, leading to the pollution of terrestrial and aquatic ecosystems (Bowles et al. 2018; Davidson et al. 2012; Galloway et al. 2008; O'Neill et al. 2018; Vitousek et al. 1997). This failure of modern agriculture has led to global disruption and acceleration of the reactive $\mathrm{N}$ cycle. Because maize is one of the most farmed and fertilized crops in the world and a staple food for many populations, finding a solution for $\mathrm{N}$ sustainability in this species is a critical need for modern agriculture (Ladha et al. 2016). Misdirection of $\mathrm{N}$ away from plants is commonly attributed to microorganisms in the soil and rhizosphere that transform and use $\mathrm{N}$. The fact that domesticated and wild Zea spp. recruit microbiomes with different suites of $\mathrm{N}$-cycling functional genes within their rhizospheres suggests that plants may be able to intervene in microbial $\mathrm{N}$ transformation activities.

In conclusion, we have shown that the domestication of teosinte into modern maize has resulted in taxonomic and $\mathrm{N}$-cycling functional group changes to the rhizosphere microbiome. Modern maize appears to have a "weakened filtering" of the microbiome colonizing the rhizosphere compared with teosinte. It still needs to be determined if and how these characteristics influence the N-cycling function of the rhizosphere microbiome in agroecosystems; however, this does suggest that functional characteristics of the ancestral microbiome have been lost through domestication (Pérez-Jaramillo et al. 2016). The more we understand about how domestication has altered the functional microbiome interactions, the closer we are to reincorporating sustainable wild genetic diversity and abandoning unsustainable traits in our modern lines to improve agricultural sustainability.

\section{ACKNOWLEDGMENTS}

We thank Dora Cohen, Maya Scott, Michael Ruiz, Julia Antonson, Anjana Krishnan, Yanjun Ma, Nicole Yana, Dongfang $\mathrm{Li}$, and Heather Lash for assistance in the greenhouse and lab; the University of Illinois Plant Care Facility staff for assistance in maintaining healthy plants; and Mark Band at the University of Illinois Functional Genomics Center for assistance with the development of multiplex PCR using the Fluidigm system.

\section{LITERATURE CITED}

Achouak, W., Abrouk, D., Guyonnet, J., Barakat, M., Ortet, P., Simon, L., Lerondelle, C., Heulin, T., and Feth, E. Z. H. 2019. Plant hosts control microbial denitrification activity. FEMS Microbiol. Ecol. 95:21.

Altschul, S. F., Madden, T. L., Schäffer, A. A., Zhang, J., Zhang, Z., Miler, W., and Lipman, D. J. 1997. Gapped BLAST and PSI-BLAST: A new generation of protein database search programs. Nucleic Acids Res. 25: 3389-3402.

Azziz, G., Monza, J., Etchebehere, C., and Irisarri, P. 2017. NirS- and NirK-type denitrifier communities are differentially affected by soil type, rice cultivar and water management. Eur. J. Soil Biol. 78:20-28.

Bardon, C., Piola, F., Bellvert, F., el Zahar Haichar, F., Comte, G., Meiffren, G., Pommier, T., Puijalon, S., Tsafack, N., and Poly, F. 2014. Evidence for biological denitrification inhibition (BDI) by plant secondary metabolites. New Phytol. 204:620-630.

Bardon, C., Poly, F., Piola, F., Pancton, M., Comte, G., Meiffren, G., and el Zahar Haichar, F. 2016. Mechanism of biological denitrification inhibition: Procyanidins induce an allosteric transition of the membranebound nitrate reductase through membrane alteration. FEMS Microbiol. Ecol. 92:fiw034.

Berbee, M. L. 2001. The phylogeny of plant and animal pathogens in the ascomycota. Physiol. Mol. Plant Pathol. 59:165-187.

Bouffaud, M. L., Kyselková, M., Gouesnard, B., Grundmann, G., Muller, D., and Moënne-Loccoz, Y. 2012. Is diversification history of maize influencing selection of soil bacteria by roots? Mol. Ecol. 21:195-206.

Bouffaud, M. L., Renoud, S., Moënne-Loccoz, Y., and Muller, D. 2016. Is plant evolutionary history impacting recruitment of diazotrophs and $\mathrm{NifH}$ expression in the rhizosphere? Sci. Rep. 6:21690.

Bouffaud, M. L., Poirier, M.-A., Muller, D., and Moënne-Loccoz, Y. 2014. Root microbiome relates to plant host evolution in maize and other Poaceae. Environ. Microbiol. 16:2804-2814.

Bowles, T. M., Atallah, S. S., Campbell, E. E., Gaudin, A. C. M., Wieder, W. R., and Grandy, A. S. 2018. Addressing agricultural nitrogen losses in a changing Climate. Nat. Sustain. 1:399-408.

Brisson, V. L., Schmidt, J. E., Northen, T. R., Vogel, J. P., and Gaudin, A. C. M. 2019. Impacts of maize domestication and breeding on rhizosphere microbial community recruitment from a nutrient depleted agricultural soil. Sci. Rep. 9:15611.

Bulgarelli, D., Garrido-Oter, R., Münch, P. C., Weiman, A., Dröge, J., Pan, Y., McHardy, A. C., and Schulze-Lefert, P. 2015. Structure and function of the bacterial root microbiota in wild and domesticated barley. Cell Host Microbe 17:392-403.

Butler, D. G., Cullis, B. R., Gilmour, A. R., Gogel, B. J., and Thompson, R. 2017. ASReml-R Reference Manual Version 4. VSN International Ltd., Hemel Hempstead, U.K.

Caporaso, J. G., Kuczynski, J., Stombaugh, J., Bittinger, K., Bushman, F. D., Costello, E. K., Fierer, N., Gonzalez Peña, A., Goodrich, J. K., Gordon, J. I., Huttley, G. A., Kelley, S. T., Knights, D., Koenig, J. E., Ley, R. E., Lozupone, C. A., McDonald, D., Muegge, B. D., Pirrung, M., Reeder, J., Sevinsky, J. R., Turnbaugh, P. J., Walters, W. A., Widmann, J., Yatsunenko, T., Zaneveld, J., and Knight, R. 2010. QIIME allows analysis of high-throughput community sequencing data. Nat. Methods 7:335-336.

Cook, R. J., Thomashow, L. S., Weller, D. M., Fujimoto, D., Mazzola, M., Bangera, G., and Kim, D.-S. 1995. Molecular mechanisms of defense by 
rhizobacteria against root disease. Proc. Natl. Acad. Sci. U.S.A. 92:41974201. https://www.pnas.org/content/pnas/92/10/4197.full.pdf

Coskun, D., Britto, D. T., Shi, W., and Kronzucker, H. J. 2017a. How plant root exudates shape the nitrogen cycle. Trends Plant Sci. 22:661-673.

Coskun, D., Britto, D. T., Shi, W., and Kronzucker, H. J. 2017b. Nitrogen transformations in modern agriculture and the role of biological nitrification inhibition. Nat. Plants 3:17074.

Davidson, E. A., David, M. B., Galloway, J. N., Goodale, C. L., Haeuber, R., Harrison, J. A., Howarth, R. W., Jaynes, D. B., Lowrance, R. R., Nolan, B. T., Peel, J. L., Pinder, R. W., Porter, E., Snyder, C. S., Townsend, A. R., and Ward, M. H. 2012. Excess nitrogen in the U.S. environment: Trends, risks, and solutions. Issues Ecol. 15:1-16. https://www.esa.org/esa/wp-content/uploads/2013/03/issuesinecology15.pdf

DeSantis, T. Z., Hugenholtz, P., Larsen, N., Rojas, M., Brodie, E. L., Keller, K., Huber, T., Dalevi, D., Hu, P., and Andersen, G. L. 2006. Greengenes, a chimera-checked 16S rRNA gene database and workbench compatible with ARB. Appl. Environ. Microbiol. 72:5069-5072.

Diamond, J. 2002. Evolution, consequences and future of plant and animal domestication. Nature 418:700-707.

Doebley, J. 2004. The genetics of maize evolution. Annu. Rev. Genet. 38:37-59.

Drinkwater, L. E., and Snapp, S. S. 2007. Nutrients in agroecosystems: Rethinking the management paradigm. Adv. Agron. 92:163-186.

Edgar, R. C. 2010. Search and clustering orders of magnitude faster than BLAST. Bioinformatics 26:2460-2461.

Edwards, J. D., Pittelkow, C. M., Kent, A. D., and Yang, W. H. 2018. Dynamic biochar effects on soil nitrous oxide emissions and underlying microbial processes during the maize growing season. Soil Biol. Biochem. 122:81-90

Favela, A., Bohn, M. O., and Kent, A. D. 2021. Maize germplasm chronosequence shows crop breeding history impacts recruitment of the rhizosphere microbiome. ISME J. 15:2454-2464.

Fierer, N., Bradford, M. A., and Jackson, R. B. 2007. Toward an ecological classification of soil bacteria. Ecology 88:1354-1364.

Fish, J. A., Chai, B., Wang, Q., Sun, Y., Brown, C. T., Tiedje, J. M., and Cole, J. R. 2013. FunGene: The functional gene pipeline and repository. Front. Microbiol. 4:1-14.

Fitzpatrick, C. R., Copeland, J., Wang, P. W., Guttman, D. S., Kotanen, P. M., and Johnson, M. T. J. 2018. Assembly and ecological function of the root microbiome across angiosperm plant species. Proc. Natl. Acad. Sci. U.S.A. 115:E1157-E1165.

Gaillard, M. D. P., Glauser, G., Robert, C. A. M., and Turlings, T. C. J. 2018. Fine-tuning the 'plant domestication-reduced defense' hypothesis: Specialist vs generalist herbivores. New Phytol. 217:355-366.

Galloway, J. N., Townsend, A. R., Erisman, J. W., Bekunda, M., Cai, Z., Freney, J. R., Martinelli, L. A., Seitzinger, S. P., and Sutton, M. A. 2008. Transformation of the nitrogen cycle: Recent trends, questions, and potential solutions. Science 320:889-892.

Gaudin, A. C. M., McClymont, S. A., and Raizada, M. N. 2011. The nitrogen adaptation strategy of the wild teosinte ancestor of modern maize, Zea mays subsp. parviglumis. Crop Sci. 51:2780-2795.

Gordon, A., and Hannon, G. J. 2014. FASTX-Toolkit. FASTQ/A short-reads pre-processing tools. http://hannonlab.cshl.edu/fastx_toolkit/

Gruber-Dorninger, C., Pester, M., Kitzinger, K., Savio, D. F., Loy, A., Rattei, T., Wagner, M., and Daims, H. 2015. Functionally relevant diversity of closely related Nitrospira in activated sludge. ISME J. 9:643655.

Hou, S., Ai, C., Zhou, W., Liang, G., and He, P. 2018. Structure and assembly cues for rhizospheric NirK- and NirS-type denitrifier communities in long-term fertilized soils. Soil Biol. Biochem. 119:32-40.

Hufford, M. B., Bilinski, P., Pyhäjärvi, T., and Ross-Ibarra, J. 2012a. Teosinte as a model system for population and ecological genomics. Trends Genet. 28:606-615.

Hufford, M. B., Xu, X., van Heerwaarden, J., Pyhäjärvi, T., Chia, J.-M., Cartwright, R. A., Elshire, R. J., Glaubitz, J. C., Guill, K. E., Kaeppler, S. M., Lai, J., Morrell, P. L., Shannon, L. M., Song, C., Springer, N. M., Swanson-Wagner, R. A., Tiffin, P., Wang, J., Zhang, G., Doebley, J., McMullen, M. D., Ware, D., Buckler, E. S., Yang, S., Ross-Ibarra, J. 2012b. Comparative population genomics of maize domestication and improvement. Nat. Genet. 44:808-811.

Ishii, S., Kitamura, G., Segawa, T., Kobayashi, A., Miura, T., Sano, D., and Okabe, S. 2014. Microfluidic quantitative PCR for simultaneous quantification of multiple viruses in environmental water samples. Appl. Environ. Microbiol. 80:7505-7511.
Jacoby, R., Peukert, M., Succurro, A., Koprivova, A., and Kopriva, S. 2017. The role of soil microorganisms in plant mineral nutrition-Current knowledge and future directions. Front. Plant Sci. 8.

Johnston-Monje, D., Mousa, W. K., Lazarovits, G., Raizada, M. N. 2014. Impact of swapping soils on the endophytic bacterial communities of predomesticated, ancient and modern maize. BMC Plant Biol. 14:233.

Jones, C. M., and Hallin, S. 2010. Ecological and evolutionary factors underlying global and local assembly of denitrifier communities. ISME J. 4:633-641.

Kuypers, M. M. M., Marchant, H. K., and Kartal, B. 2018. The microbial nitrogen-cycling network. Nat. Rev. Microbiol. 16:263-276.

Ladha, J. K., Tirol-Padre, A., Reddy, C. K., Cassman, K. G., Verma, S., Powlson, D. S., van Kessel, C., Richter, D. d. B., Chakraborty, D., and Pathak, H., 2016. Global nitrogen budgets in cereals: A 50-year assessment for maize, rice, and wheat production systems. Sci. Rep. 6:19355.

Lau, J. A., and Lennon, J. T. 2012. Rapid responses of soil microorganisms improve plant fitness in novel environments. Proc. Natl. Acad. Sci. U.S.A. 109:14058-14062.

Li, D., Voigt, T. B., and Kent, A. D. 2016. Plant and soil effects on bacterial communities associated with Miscanthus $\times$ giganteus rhizosphere and rhizomes. GCB Bioenergy 8:183-193.

Love, M. I., Huber, W., and Anders, S. 2014. Moderated estimation of fold change and dispersion for RNA-Seq data with DESeq2. Genome Biol. 15:550.

Ma, Y., Zilles, J. L., and Kent, A. D. 2019. An evaluation of primers for detecting denitrifiers via their functional genes. Environ. Microbiol. 21: 1196-1210.

Madsen, E. L. 2011. Microorganisms and their roles in fundamental biogeochemical cycles. Curr. Opin. Biotechnol. 22:456-464.

Magoč, T., and Salzberg, S. L. 2011. FLASH: Fast length adjustment short reads improve genome assemblies. Bioinformatics 27:2957-2963.

Martín-Robles, N., Lehmann, A., Seco, E., Aroca, R., Rillig, M. C., and Milla, R. 2018. Impacts of domestication on the arbuscular mycorrhizal symbiosis of 27 crop species. New Phytol. 218:322-334.

Matsuoka, Y., Vigouroux, Y., Goodman, M. M., Sanchez G, J., Buckler, E., and Doebley, J. 2002. A single domestication for maize shown by multilocus microsatellite genotyping. Proc. Natl. Acad. Sci. U.S.A. 99:6080-6084.

McMurdie, P. J., and Holmes, S. 2013. Phyloseq: An R package for reproducible interactive analysis and graphics of microbiome census data. PLoS One 8:e61217.

Meyer, R. S., DuVal, A. E., and Jensen, H. J. 2012. Patterns and processes in crop domestication: An historical review and quantitative analysis of 203 global food crops. New Phytol. 196:29-48.

Moreau, D., Bardgett, R. D., Finlay, R. D., Jones, D. L., and Philippot, L. 2019. A plant perspective on nitrogen cycling in the rhizosphere. Funct. Ecol. 33:540-552.

Morris, A., Meyer, K., and Bohannan, B. 2020. Linking microbial communities to ecosystem functions: What we can learn from genotype-phenotype mapping in organisms. Phil. Trans. R. Soc. B 375:20190244.

O’Neill, D. W., Fanning, A. L., Lamb, W. F., and Steinberger, J. K. 2018. A good life for all within planetary boundaries. Nat. Sustain. 1:88-95.

Oksanen, J., Kindt, R., Legendre, P., O'Hara, B., and Stevens, M. H. H. 2007. The Vegan Package. Community Ecology Package.

Ouyang, Y., Evans, S. E., Friesen, M. L., and Tiermann, L. K., 2018. Effect of nitrogen fertilization on the abundance of nitrogen cycling genes in agricultural soils: A meta-analysis of field studies. Soil Biol. Biochem. 127:71-78.

Pajares, S., and Bohannan, B. J. M. 2016. Ecology of nitrogen fixing, nitrifying, and denitrifying microorganisms in tropical forest soils. Front. Microbiol. 7.

Panke-Buisse, K., Poole, A. C., Goodrich, J. K., Ley, R. E., and KaoKniffin, J. 2015. Selection on soil microbiomes reveals reproducible impacts on plant function. ISME J. 9:980-989.

Peiffer, J. A., Spor, A., Koren, O., Jin, Z., Tringe, S. G., Dangl, J. L., Buckler, E. S., and Ley, R. E. 2013. Diversity and heritability of the maize rhizosphere microbiome under field conditions. Proc. Natl. Acad. Sci. U.S.A. 110:6548-6553.

Pérez-Jaramillo, J. E., Carrión, V. J., de Hollander, M., and Raaijmakers, J. M. 2018. The wild side of plant microbiomes. Microbiome 6:143.

Pérez-Jaramillo, J. E., Mendes, R., and Raaijmakers, J. M. 2016. Impact of plant domestication on rhizosphere microbiome assembly and functions. Plant Mol. Biol. 90:635-644. 
Philippot, L., Hallin, S., and Schloter, M. 2007. Ecology of denitrifying prokaryotes in agricultural soil. Adv. Agron. 96:249-305.

Philippot, L., Raaijmakers, J. M., Lemanceau, P., and van der Putten, W. H. 2013a. Going back to the roots: The microbial ecology of the rhizosphere. Nat. Rev. Microbiol. 11:789-799.

Philippot, L., Spor, A., Hénault, C., Bru, D., Bizouard, F., Jones, C. M., Sarr, A., and Maron, P.-A. 2013b. Loss in microbial diversity affects nitrogen cycling in soil. ISME J. 7:1609-1619.

Porter, S. S., and Sachs, J. L. 2020. Agriculture and the disruption of plant-microbial symbiosis. Trends Ecol. Evol. 35:426-439.

R Core Team. 2013. R: A Language and Environment for Statistical Computing. R Foundation for Statistical Computing, Vienna, Austria. http://www.R-project.org/

Sambrook, J., and Russell, D. W. 2001. Molecular Cloning: A Laboratory Manual, Vol. 2, 3rd Ed. Cold Spring Harbor Laboratory Press, New York

Schimel, J. P, Bennett, J., and Fierer, N. 2005. Microbial community composition and soil nitrogen cycling: Is there really a connection? Pages 171-188 in: Biological Diversity and Function in Soils. R. D. Bardgett, M. B. Usher, and D. W. Hopkins, eds. Cambridge University Press, Cambridge, U.K.

Schmidt, J. E., Mazza Rodrigues, J. L., Brisson, V. L., Kent, A., and Gaudin, A. C. M. 2020. Impacts of directed evolution and soil management legacy on the maize rhizobiome. Soil Biol. Biochem. 145:107794.

Shenton, M., Iwamoto, C., Kurata, N., and Ikeo, K. 2016. Effect of wild and cultivated rice genotypes on rhizosphere bacterial community composition. Rice (N. Y.) 9:42.

Spasov, E., Tsuji, J. M., Hug, L. A., Doxey, A. C., Sauder, L. A., Parker, W. J., and Neufeld, J. D. 2020. High functional diversity among Nitrospira populations that dominate rotating biological contactor microbial communities in a municipal wastewater treatment plant. ISME J. 14:1857-1872.

Subbarao, G. V., Sahrawat, K. L., Nakahara, K., Rao, I. M., Ishitani, M., Hash, C. T., Kishii, M., Bonnett, D. G., Berry, W. L., and Lata, J. C. 2013. A paradigm shift towards low-nitrifying production systems: The role of biological nitrification inhibition (BNI). Ann. Bot. (Lond.) 112:297-316.

Swanson-Wagner, R., Briskine, R., Schaefer, R., Hufford, M., Ross-Ibarra, J., Myers, C. L., Tiffin, P., and Springer, N. M. 2012. Reshaping of the maize transcriptome by domestication. Proc. Natl. Acad. Sci. U.S.A. 109: 11878-11883.

Szoboszlay, M., Lambers, J., Chappell, J., Kupper, J. V., Moe, L. A., and McNear, D. H., Jr. 2015. Comparison of root system architecture and rhizosphere microbial communities of balsas teosinte and domesticated corn cultivars. Soil Biol. Biochem. 80:34-44.

Van Deynze, A., Zamora, P., Delaux, P.-M., Heitmann, C., Jayaraman, D., Rajasekar, S., Graham, D., Maeda, J., Gibson, D., Schwartz, K. D., Berry, A. M., Bhatnagar, S., Jospin, G., Darling, A., Jeannotte, R., Lopez, J., Weimer, B. C., Eisen, J. A., Shapiro, H.-Y., Ané, J.-M., and Bennett, A. B. 2018. Nitrogen fixation in a landrace of maize is supported by a mucilage-associated diazotrophic microbiota. PLoS Biol. 16:e2006352.
Vitousek, P. M., Aber, J. D., Howarth, R. W., Likens, G. E., Matson, P. A., Schindler, D. W., Schlesinger, W. H., and Tilman, D. G. 1997. Human alteration of the global nitrogen cycle: Sources and consequences. Ecol. Appl. 7:737-750.

Wagner, M. R., Lundberg, D. S., Coleman-Derr, D., Tringe, S. G., Dangl, J. L., and Mitchell-Olds, T. 2014. Natural soil microbes alter flowering phenology and the intensity of selection on flowering time in a wild Arabidopsis relative. Ecol. Lett. 17:717-726.

Walters, W. A., Jin, Z., Youngblut, N., Wallace, J. G., Sutter, J., Zhang, W., González-Peña, A., Peiffer, J., Koren, O., Shi, Q., Knight, R., del Rio, T. G., Tringe, S. G., Buckler, E. S., Dangl, J. L., and Ley, R. E. 2018. Large-scale replicated field study of maize rhizosphere identifies heritable microbes. Proc. Natl. Acad. Sci. U.S.A. 115:7368-7373.

Wang, L., Beissinger, T. M., Lorant, A., Ross-Ibarra, C., Ross-Ibarra, J., and Hufford, M. B. 2017. The interplay of demography and selection during maize domestication and expansion. Genome Biol. 18:215.

Wang, X., Chen, Q., Wu, Y., Lemmon, Z. H., Xu, G., Huang, C., Liang, Y., Xu, D., Li, D., Doebley, J. F., and Tian, F. 2018. Genome-wide analysis of transcriptional variability in a large maize-teosinte population. Mol. Plant 11:443-459.

Wei, W., Isobe, K., Nishizawa, T., Zhu, L., Shiratori, Y., Ohte, N., Koba, K., Otsuka, S., and Senoo, K. 2015. Higher diversity and abundance of denitrifying microorganisms in environments than considered previously. ISME J. 9:1954-1965.

Whitehead, S. R., Martin, M. M., and Poveda, K. 2017. Domestication impacts on plant-herbivore interactions: A meta-analysis. Philos. Trans. R. Soc. B 372:20160034.

Wickham, H., Navarro, D., and Pedersen, T. L. 2007. ggplot2-Elegant graphics for data analysis. https://ggplot2-book.org/

Wright, S. I., Bi, I. V., Schroeder, S. G., Yamasaki, M., Doebley, J. F., McMullen, M. D., and Gaut, B. S. 2005. The effects of artificial selection on the maize genome. Science 308:1310-1314.

Xing, X., Koch, A. M., Jones, M. P., Ragone, D., Murch, S., and Hart, M. M. 2012. Mutualism breakdown in breadfruit domestication. Proc. R. Soc. B 279:1122-1130.

Xu, G., Cao, J., Wang, X., Chen, Q., Jin, W., Li, Z., and Tian, F. 2019. Evolutionary metabolomics identifies substantial metabolic divergence between maize and its wild ancestor, teosinte. Plant Cell 31:1990-2009.

Xu, L., Naylor, D., Dong, Z., Simmons, T., Pierroz, G., Hixson, K. K., Kim, Y.-M., Zink, E. M., Engbrecht, K. M., Wang, Y., Gao, C., DeGraaf, S., Madera, M. A., Sievert, J. A., Hollingsworth, J., Birdseye, D., Scheller, H. V., Hutmacher, R., Dahlberg, J., Jansson, C., Taylor, J. W., Lemaux, P. G., and Coleman-Derr, D. 2018. Drought delays development of the sorghum root microbiome and enriches for monoderm bacteria. Proc. Natl. Acad. Sci. U.S.A. 115:E4284-e4293.

Yeoh, Y. K., Dennis, P. G., Paungfoo-Lonhienne, C., Weber, L., Brackin, R., Ragan, M. A., Schmidt, S., and Hugenholtz, P. 2017. Evolutionary conservation of a core root microbiome across plant phyla along a tropical soil chronosequence. Nat. Commun. 8:215. 